\title{
Identifying User Requirements for an Integrated E-Health Unit for Diabetes Mellitus
}

\author{
Maria Tzilini ${ }^{1}$, Dimitris Folinas ${ }^{2, *}$ and Kyriakos Kazakos ${ }^{3}$ \\ 1 Department of Civil Infrastructure Engineering, International Hellenic University, 14th km Thessaloniki, \\ 57001 Nea Moudania, Greece; mtzilini@cie.teithe.gr \\ 2 Department of Supply Chain Management, International Hellenic University, 60100 Katerini, Greece \\ 3 Department of Nursing, International Hellenic University, 14th km Thessaloniki, \\ 57001 Nea Moudania, Greece; kkazakos@ihu.gr \\ * Correspondence: dfolinas@gmail.com or folinasd@ihu.gr
}

Citation: Tzilini, M.; Folinas, D.; Kazakos, K. Identifying User Requirements for an Integrated E-Health Unit for Diabetes Mellitus. Diabetology 2021, 2, 65-76. https:// doi.org/10.3390/diabetology2020006

Academic Editor: Peter Clifton

Received: 2 April 2021

Accepted: 29 April 2021

Published: 2 May 2021

Publisher's Note: MDPI stays neutral with regard to jurisdictional claims in published maps and institutional affiliations.

Copyright: (C) 2021 by the authors. Licensee MDPI, Basel, Switzerland. This article is an open access article distributed under the terms and conditions of the Creative Commons Attribution (CC BY) license (https:// creativecommons.org/licenses/by/ $4.0 /)$.

\begin{abstract}
Continuity of Care" is the main prerequisite for the unhindered movement of people across borders within the European Union (EU). The COntinuity of care in MEtabolic diseases through modern TECHnology (COMETECH) project aims to address the problem of inadequate access to health system services to people who live in isolated communities in Greece and North Macedonia cross-border areas. As the project is almost completed, 4 e-health units-2 in each country-have been established in isolated and deprived communities, aiming at introducing "Continuity of Care" for patients with diabetes in the border region between those countries. The establishment of the e-health units allows affordable access to medical services within Greece-North Macedonia cross-border area. These units (equipped with state-of-the-art medical devices, supported by an advanced software application and medical staff) record data of local people and offer valuable and high-quality medical care services. The records of the EU citizens using the COMETECH services are safely and easily accessible by their physicians. This paper presents the user requirements of e-health units and the medical devices that are set up for the COMETECH Project for helping people with diabetes in the targeted countries.
\end{abstract}

Keywords: telehealth; diabetes mellitus; user requirements; e-health unit; medical devices

\section{Introduction}

Telehealth and telemedicine have evolved quickly in recent years, suggesting that they will continue to develop at a rapid pace [1,2]. As technology advances and organizations become more familiar with platforms and service options, minimum built-environment standards to support these practices may need to be refined [2-4]. Moreover, even some of the most prestigious health care systems in many countries acknowledge that they learn from their mistakes and make necessary corrections to the physical environment or communications equipment - an approach that not all organizations may be able to afford, especially during crises and/or disasters such as the Covid-19 pandemic [5-7].

Many research initiatives and projects have confirmed that telehealth can support the effective and efficient application of continuity of care in diabetes [8-12]. Crossen, Raymond and Neinstein [13] proposed 10 steps for successfully implementing a diabetes telehealth program. Two of them are: Standardizing telehealth visit processes, and electronic health record (EHR) integration. Moreover, as Krupinski (2014) argues, "The environments within which healthcare interactions take place are going to be as varied as the providers and patients, but the fundamental concerns and principles about creating spaces that facilitate clear, open and caring communication should guide our efforts to successfully - and with proper integrity, security and respect for privacy — reach out and connect with those who need care: anywhere, anytime" [14]. Based on the above, key parts in any telehealth initiative are: (1) e-health units and (2) the medical devices that the e-health units are equipped. 
The main objective of this paper is to present the user requirements of e-health units and the medical devices that are set up for the COMETECH Project in order to help people with diabetes in the targeted countries. These are the deliverables of a research project that proposes innovative telehealth technologies to address the problem of inadequate access to the health system services dedicated to diabetes for people who live in isolated communities in Greece and North Macedonia cross-border areas.

The research project is titled COntinuity of care in MEtabolic diseases through modern TECHnology (COMETECH). It is under the Interreg Pre-Accession Assistance (IPA) CrossBorder Cooperation (CBC) Programme "Greece-Republic of North Macedonia 2014-2020", which is a cross-border cooperation program co-financed by the European Union. The strategy statement of the program is "to enhance territorial cohesion by improving living standards and employment opportunities holding respect to the environment and by using the natural resources for upgrading of the tourism product".

According to the International Diabetes Federation, diabetes mellitus (DM) affects about $8 \%$ of the population in Greece and North Macedonia, and 60 million in the European Region, or about $10.3 \%$ of men and $9.6 \%$ of women aged 25 years and over [14]. Unfortunately, about $46 \%$ of people in the EU with diabetes are undiagnosed, thus stressing the importance of prevention and early diagnosis [15]. The vast majority of patients with DM type 1 are adolescents and children. However, the middle-aged and elderly population are more vulnerable to DM type 2. On the other hand, the World Health Organization (WHO) has recognized obesity as a global epidemic [16]. More than $16 \%$ of the adult population in Europe is obese and one in three children are overweight or obese [17]. The prevalence of obesity in Greece and North Macedonia is about 20\% [18].

DM and obesity are metabolic diseases with serious health impacts and they both comprise cardio-vascular risk factors. DM is also a risk factor for developing small and large vessel complications (e.g., nephropathy, retinopathy, heart disease, stroke, peripheral arterial disease). In the EU, the total costs for DM are over 150 billion Euros/year (11\% of the total health costs) [19]. The mean DM-related expenditure/person in Greece is about 2,450, and in North Macedonia it is 390 Euros/year [18]. The majority of the expenditures are due to the treatment of diabetes complications, like end-stage renal failure and dialysis, peripheral arterial disease and amputations, retinopathy, etc. The costs for the provision of health care are higher for people living in rural than in urban areas, which can be attributed in part to the greater transport costs in order to reach health system services.

Unfortunately, there are a lot of isolated and deprived communities in the GreeceNorth Macedonia cross-border areas, who have tremendous difficulties accessing public health services. More than $16 \%$ of the population of Greece and North Macedonia were hospitalized, and about $25 \%$ of the population visited a doctor, at least once, last year [20]. In most European countries, the education of the population and also of the health professionals with respect to these diseases has little or no financial support [19]. Therefore, the need for general awareness and education of the population with respect to metabolic diseases with current, comprehensive information is of great importance. Early prevention and diagnosis, as well as proper health care, are essential human rights. Therefore, a lot of action should be taken with respect to this target population in order to achieve a satisfying standard.

According to the Organization for Economic Co-operation and Development, it is the health itself of a population (more than education or investment) that is the chief determinant of economic development of a region [21]. It is for this reason that this proposal was introduced to contribute, to a significant degree, to the general welfare of its regions. By using 3rd- and 4th-generation Global System for Mobile Communications (GSM) services, as well as fast Internet connections, COMETECH aims to be an exceptionally innovative means for introducing Continuity of Care to Greek and North Macedonia health practices.

The rest of the paper is organized as follows. First, an overview of the COMETECH project is provided. Then the requirements of the e-health units and the medical devices are presented and analyzed. 


\section{Telehealth Research Project Overview}

The COMETECH project aims to address the problem of inadequate access to health system services to people who live in isolated communities in the Greece-Republic of North Macedonia cross-border areas (Figure 1). COMETECH is implemented by a partnership consisting of five partners from both participating countries: (1) International Hellenic University, (2) Florina Prefectural General Hospital, and (3) Medical Association of Thessaloniki from Greece, as well as (4) Clinical Hospital Bitola, and (5) General Hospital Veles from North Macedonia. The total project budget amounts to 1,018,189 Euros, and its duration is 24 months. COMETECH project focused on patients of diabetes mellitus (DM).

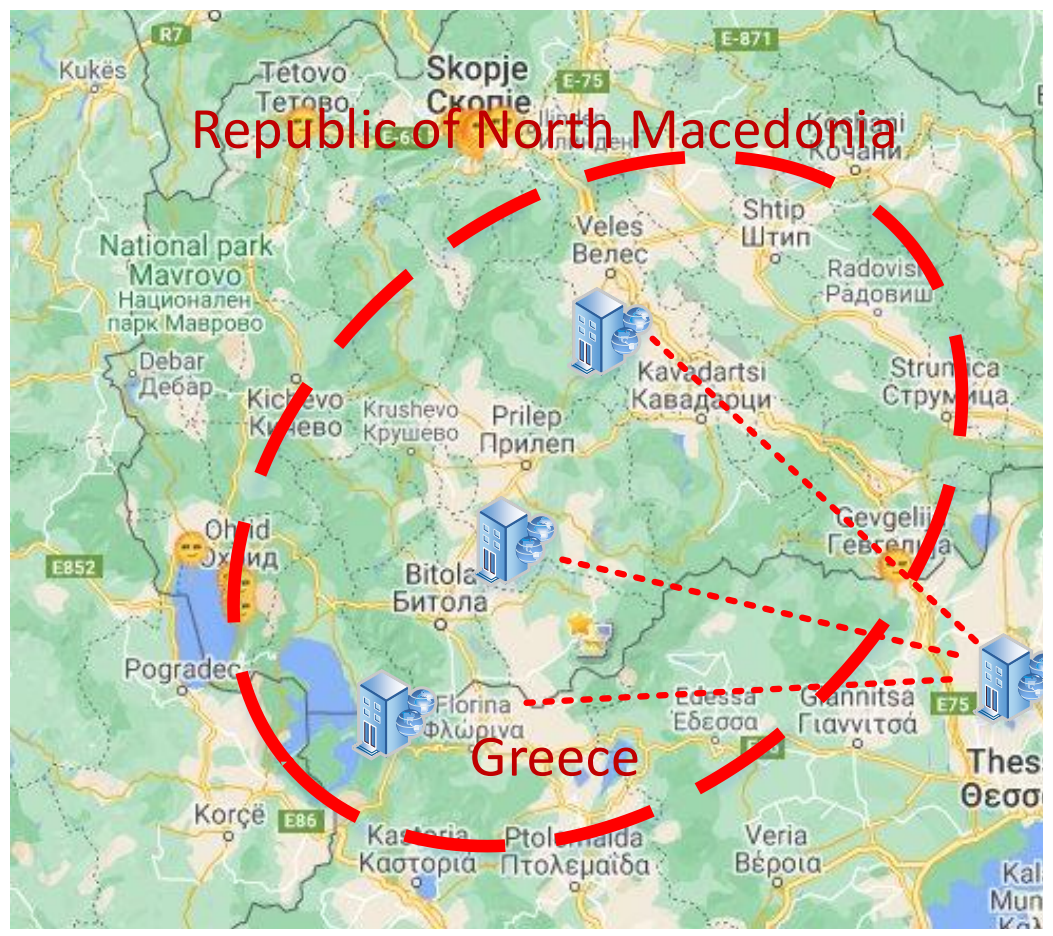

Figure 1. Examined geographic areas.

The project establishes four e-health units -2 in each country-in isolated and deprived communities that collaborate with each other, aiming at introducing "Continuity of Care" in the border region between the Republic of North Macedonia and Greece. These units (equipped with state-of-the-art medical devices, supported by an advanced software application and medical staff) record data of local people and offer valuable and highquality medical care services. The records of the citizens using the COMETECH services can safely and easily accessible by their physicians adopting the Quality of Electronic Health Record System (EHRS).

As a (sub-)information system, an EHRS is a product resulting from information management, which can be considered the manufacturing process of EHRS. Furthermore, the involved public bodies can use COMETECH services as a tool for introducing highquality continuity of health care in their respective regions.

The COMETECH specific objectives are the following:

- To support collaboration between research teams from the Republic of North Macedonia and Greece of scientists from different scientific fields (such as doctors, biologists, etc.) and closer cooperation among the two national health care systems to develop a common strategy for prevention, early diagnosis and treatment of obesity, DM and cardio-vascular disease (CVD).

- To raise awareness of the local and national authorities regarding the above health issues. 
- To inform the regional population on the prevention, diagnosis, and treatment of DM, obesity and CVD.

- To identify the environmental and other risk factors that are involved in the development of DM, obesity, and CVD in the population that participate in the project.

- To facilitate access for doctors on both sides of the border to their patients' data through telehealth.

- To support the life-long education of the COMETECH involved population and medical practitioners by using their telehealth interaction with experts as the means for training.

Specifically, the e-health units can record the data of local people, offer high-quality medical care services, and inform people about risks. Participating in this (pilot) study was a population of more than 1000 citizens (equally balanced) of the Greece-North Macedonia cross-border territory. The citizens were examined thoroughly for DM, obesity and CVD. The e-health units provided the patients with the opportunity of live communication with experts (dialectologists, cardiologists, ophthalmologists, dieticians, nurse educators) via teleconferencing. Users also had online access to their results from a laptop, tablet, or mobile (smartphone). Authorized users of the hospitals of the program (Bitola, Florina, Veles) were able to access the web application to evaluate the medical data and patient measurements to provide medical advice to the physician of the telemedicine units where required.

The system was installed on a central server of the International Hellenic University in Thessaloniki, Greece, where data were collected, tested for quality and measurements of biological parameters of patients were stored, which were sent wirelessly from remote locations, i.e., health units and the hospitals (Bitola, Florina, Veles), as well as the Central Coordination Center in Thessaloniki, had authorized access.

The architecture of the e-health units and their key functionalities are illustrated below (Figure 2):

\section{First e-health unit (located in Florina, Greece)}

$\begin{gathered}\text { Second e-health unit } \\ \text { (located in Bitola, North } \\ \text { Macedonia) }\end{gathered}$
$\begin{gathered}\text { Third e-health unit } \\ \text { (located in Veles, North } \\ \text { Macedonia) }\end{gathered}$
- Each patient is examined
thoroughly in rotation by
health professionals
- Medical data are submitted to
the central unit

Central e-health unit (located in Thessaloniki, Greece)

Figure 2. Topology of COMETECH platform.

The following section presents and briefly analyzes the requirements for the medical devices, as well as the e-health units. 


\section{User Requirements}

\subsection{Medical Device Requirements}

Under the implementation of the project's plan, 13 high-tech medical devices were used by health professionals. Moreover, the examination of the patients followed a specific and predetermined order. Initially, after the welcome, patients were thoroughly informed about the screening process, and if he/she agreed to participate in the procedure, he/she signed the informed written consent form. The informed written consent form was written in the language of the patient in order for it to be fully understood and for agreement to participate in the procedure to be given. The recording of the demographic information followed. An arithmetic code, rather than the patient's full name, was recorded in order to protect personal data. Medical history was then obtained, which was also recorded in the system. The following activity relationship diagram (Figure 3) of the e-health unit illustrates the various scenarios of flow/movement of the patient. Moreover, the medical devices that were implemented are provided.

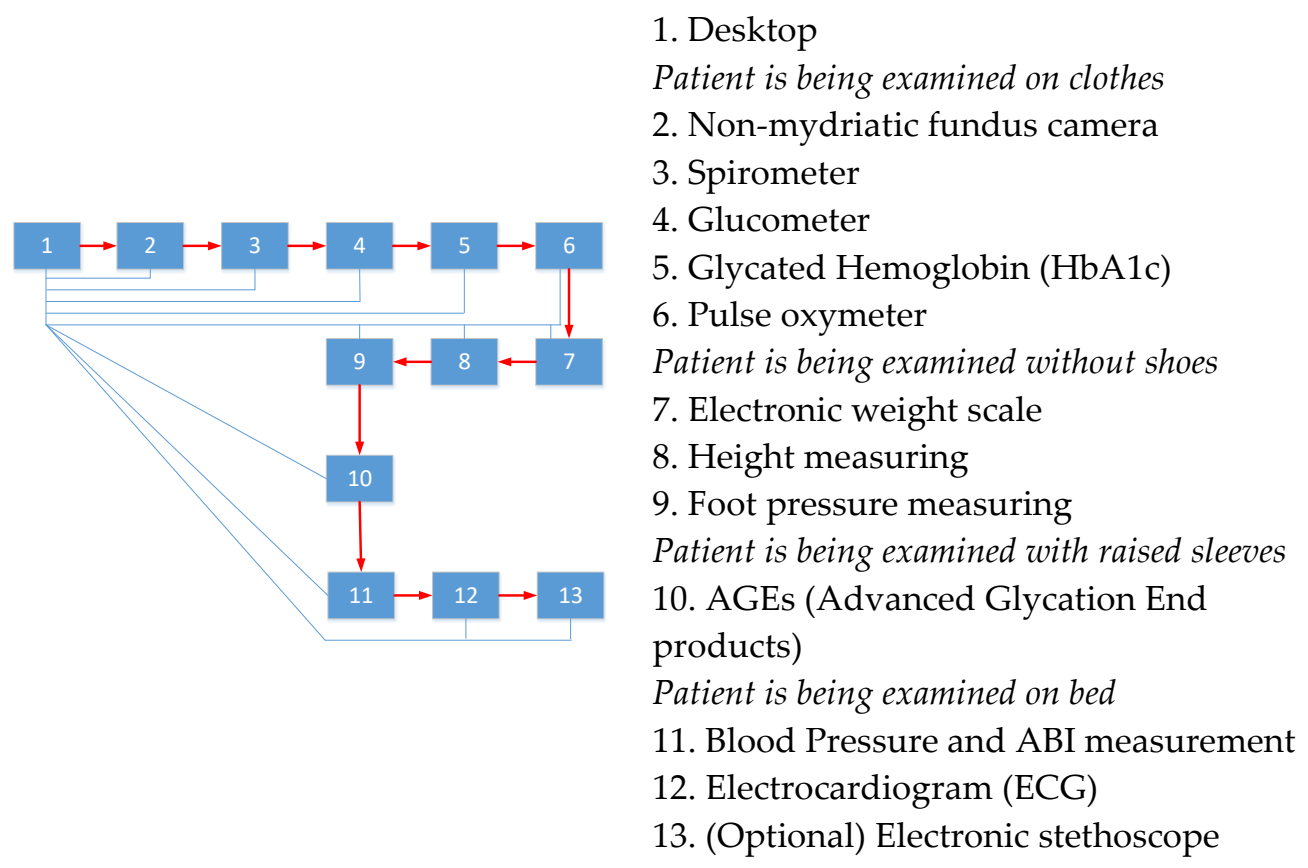

Figure 3. Activity relationship diagram of the e-health unit.

Short description, functionalities and procedures for the use of medical devices are provided as follows:

1. Column scale (height scale, stadiometer). The column scale used in the COMETECH project is an electronic height measurement device with high accuracy. It is battery supplied and features a mechanism on the headpiece to ensure that the patient is in the right position and thereby contribute to obtaining accurate measurements.

2. Blood Glucose (blood sugar) Monitoring System Device. The procedure is very easy and typical for this important test. After completion of the examination, the result is transferred and recorded in the software application platform.

3. A hemoglobin $\mathrm{A} 1 \mathrm{c}(\mathrm{HbA1c})$ test measures the amount of glucose attached to hemoglobin with a color touch display and easy handling device.

4. Electronic Stethoscope is a wireless device in which the sounds are transmitted electronically, provides noise reduction, signal enhancement, and both visual and audio output. In the project, this device also combines ambient noise reduction technology and frictional noise dampening features with amplification, Bluetooth technology, and a friendly user interface. 
5. The electrocardiogram (ECG) test is applied using a battery-powered portable device that records the heart's electrical activity. It can collect ECG signals simultaneously and print ECG waveform with a thermal printing system.

6. The spirometer test (spirogram) is made by a spirometer device, for measuring the volume of air inspired and expired by the lungs. Once again, after completion of the examination, the results are automatically transferred and recorded in the software application platform.

7. The blood pressure monitor, with ankle brachial index (ABI) device, includes four blood pressure cuffs for both arms and both legs, which measure electronically the blood pressure simultaneously at the above four points and automatically calculates the ABI index.

8. The foot scanner is a lightweight, portable plantar pressure measurement device that records all the relevant information needed to analyze the foot's behavior. The device automatically measures the plantar pressures and analyzes them. A straightforward interpretation of the foot's function is displayed via detailed images and statistical graphs. After completion of the examination, the results are automatically transferred and recorded in the application.

9. The advanced glycated end product monitoring device is a portable non-invasive monitoring device that uses ultra-violet light to excite auto fluorescence in human skin tissue. The AGE Reader has a light source that illuminates the tissue of interest (usually the arm).

10. The non-mydriatic retinal camera (fundus camera) is a specially crafted low-power microscope fitted with a high-definition camera. It produces true color fundus photos of excellent quality. Additionally, it guarantees fully automated alignment, autofocus and auto shoot. The photographs taken can also be kept on file, resulting in a far more detailed and accurate optical history to be built up of the eye health over time.

11. The pulse oximeter finger pulse blood oxygen $\mathrm{SPO}_{2}$ monitor is a small, portable cliplike battery-operated device for monitoring blood oxygen saturation and detecting the pulse rate non-invasively.

12. The ECG Holter Monitoring system is a type of ambulatory electrocardiography device, a portable device for cardiac monitoring (the monitoring of the electrical activity of the cardiovascular system) for at least 24 to $48 \mathrm{~h}$.

13. The wireless weight scale measures BMI, lean, bone, muscle, water mass body fat, and visceral fat. It also estimates daily caloric intake, displays room temperature and humidity, tracks data, graphs, history, etc. As above, after completion of the examination, the results are automatically transferred and recorded in the software application platform.

\subsection{E-Health Unit Requirements}

Once the various medical devices were selected, it was ensured that the room for the e-health unit was set up appropriately [22]. The design of a comfortable and private workspace can improve telehealth practice efficiency, enhance the virtual patient experience, and create an ergonomically environment that supports medical services in the telehealth paradigm. The appropriate location and configuration of space used for an e-health unit can help all participants (doctors, nurses, and patients) reduce the barrier posed by the physical distance between them. E-health units at which clinical telehealth services for DM are provided should meet the following requirements, which directly relate to the services provided and patient needs [22-24]:

- Security. Firstly, the telehealth equipment/medical devices should be locked in secure locked cabinets, especially those with a high price (e.g., digital cameras, electrocardiogram devices, etc.). Secondly, additional security sensors are required for monitoring the place and parameters such as heat, humidity, movements, etc.

- Privacy. The telehealth room must provide speech and visual privacy from external observers with adjacent spaces based on the telehealth room's clinical function. 
- Confidentiality. The room must ensure patient confidentiality.

- Connectivity. The room should be equipped with an Internet connection for the software application.

Several factors influence the design of the space used for the e-health unit. In general, the location of the room can be critical, but there are some other factors that can be considered equally significant. The wide variety of telehealth solutions has diverse infrastructure requirements. However, by synthesizing the existing literature [22,24-31], the following critical factors can be identified:

- Location

- Space/size

- Layout

- Acoustics

- $\quad$ Lighting

- Equipment

The above factors are described in more details in the following sections:

Location. A location that is convenient for users, and encourages their participation in and support for telehealth paradigms. Most organizations choose to locate a fixed space(s) dedicated for these initiatives. For the COMETECH project, all medical partners established dedicated rooms so that they were always available when needed. For the location/position in various hospitals, a basic criterion was the proximity to specific rooms such as washrooms, change room facilities, patient reception areas and outpatient registration counters. Moreover, emergency resuscitation equipment are important considerations, as is wheel-chair accessibility.

Space/size. In general, the space and size of the room depend on the type of clinical service being provided, the type of equipment required and the number of people the room accommodates [32]. The e-health unit room must be large enough to allow for easy movement around the patient without disrupting the consultation. For the COMETECH project, the size of the space was selected to be large enough to comfortably accommodate the number of users (doctor, nurse, and patients) expect, while also housing the telehealth system, peripheral devices, exam table, patient presenter, hand-washing station, documentation area, and furniture. Since it is mainly dedicated to diabetes, it is necessary to perform gait studies and therefore enough space is needed for the patient to take 8-10 steps. Thus, the telehealth room must have about $5 \mathrm{~m}$ of unimpeded walking space. Furthermore, the area has a ceiling of approximately $3 \mathrm{~m}$. Participants should sit at least 1 to $2 \mathrm{~m}$ from the main teleconferencing camera and monitor so that the remote viewers have a suitable image [29].

Layout. Regarding the layout, the various medical devices are situated in front of the participants. Specifically, doctors, nurses and patients sit directly in front of the camera so that they do not look like they are looking upwards, downwards, or sideways. The choice of furniture helps to create a pleasant atmosphere and foster a climate of trust, especially in a telehealth context, in which patients should feel comfortable confiding in the clinician. This choice and layout in general can work very well for small groups such as in the COMETECH project (Table 1). The examination table or patient's chair is not placed in front of a window, as this causes backlighting and degrades image quality [32]. Moreover, for the COMETECH project, systematic layout planning (SLP) was followed for the preparation of the e-health units' layout. SLP is a tool used to arrange a workplace by locating areas with high frequency and logical relationships close to each other [33]. It is applied to optimize the existing layout. The application is expected to make the fastest material flow with the lowest cost and least amount of material handling $[34,35]$. Then the space requirement for each part table was developed. 
Table 1. Space requirement for each part.

\begin{tabular}{|c|c|}
\hline Devices & Space Area $\left(\mathrm{m}^{2}\right)$ \\
\hline 1. Desktop & 1 \\
\hline 2. Non-mydriatic fundus camera & 2.5 \\
\hline 3. Spirometer & 1 \\
\hline 4. Glucometer & 1 \\
\hline 5. Glycated Hemoglobin (HbA1c) & 1 \\
\hline 6. Pulse oxymeter & 1 \\
\hline 7. Electronic weight scale & 1 \\
\hline 8. Height measuring & 1 \\
\hline 9. Foot pressure measuring & 1 \\
\hline 10. AGEs (Advanced Glycation End products) & 1 \\
\hline 11. Blood Pressure and ABI measurement & 6 \\
\hline 12. Electrocardiogram (ECG) & 6 \\
\hline 13. Electronic stethoscope & 1 \\
\hline Total area & $24.5 \mathrm{~m}^{2}$ \\
\hline
\end{tabular}

Finally, the layout of the Systematic Layout Planning was produced (Table 2) depicting the need for closeness of the devices based on the examination process.

Table 2. SLP closeness values between every device $\left(^{*}\right)$.

\begin{tabular}{|c|c|c|c|c|c|c|c|c|c|c|c|c|c|}
\hline Devices & 1 & 2 & 3 & 4 & 5 & 6 & 7 & 8 & 9 & 10 & 11 & 12 & 13 \\
\hline 1. Desktop & & & & & & & & & & & & & \\
\hline 2. Non-mydriatic fundus camera & A & & & & & & & & & & & & \\
\hline 3. Spirometer & I & A & & & & & & & & & & & \\
\hline 4. Glucometer & I & $\mathrm{O}$ & A & & & & & & & & & & \\
\hline 5. Glycated hemoglobin (HbA1c) & I & $\mathrm{O}$ & $\mathrm{O}$ & A & & & & & & & & & \\
\hline 6. Pulse oxymeter & I & $\mathrm{O}$ & $\mathrm{O}$ & $\mathrm{O}$ & A & & & & & & & & \\
\hline 7. Electronic weight scale & I & $\mathrm{O}$ & $\mathrm{O}$ & $\mathrm{O}$ & $\mathrm{O}$ & A & & & & & & & \\
\hline 8. Height measuring & I & $\mathrm{O}$ & $\mathrm{O}$ & $\mathrm{O}$ & $\mathrm{O}$ & $\mathrm{O}$ & $\mathrm{E}$ & & & & & & \\
\hline 9. Foot pressure measuring & I & $\mathrm{O}$ & $\mathrm{O}$ & $\mathrm{O}$ & $\mathrm{O}$ & $\mathrm{O}$ & $\mathrm{O}$ & E & & & & & \\
\hline 10. AGEs (advanced glycation end products) & I & $\mathrm{O}$ & $\mathrm{O}$ & $\mathrm{O}$ & $\mathrm{O}$ & $\mathrm{O}$ & $\mathrm{O}$ & $\mathrm{O}$ & $\mathrm{E}$ & & & & \\
\hline 11. Blood pressure and ABI measurement & I & $\mathrm{O}$ & $\mathrm{O}$ & $\mathrm{O}$ & $\mathrm{O}$ & $\mathrm{O}$ & $\mathrm{O}$ & $\mathrm{O}$ & $\mathrm{O}$ & A & & & \\
\hline 12. Electrocardiogram (ECG) & I & $\mathrm{O}$ & $\mathrm{O}$ & $\mathrm{O}$ & $\mathrm{O}$ & $\mathrm{O}$ & $\mathrm{O}$ & $\mathrm{O}$ & $\mathrm{O}$ & $\mathrm{O}$ & $\mathrm{A}$ & & \\
\hline 13. Electronic stethoscope & I & $\mathrm{O}$ & $\mathrm{O}$ & $\mathrm{O}$ & $\mathrm{O}$ & $\mathrm{O}$ & $\mathrm{O}$ & $\mathrm{O}$ & $\mathrm{O}$ & $\mathrm{O}$ & $\mathrm{O}$ & A & \\
\hline
\end{tabular}

(*) A: Absolutely necessary, E: Especially important, I: Important, O: Ordinary.

Acoustics and sound considerations. In general, a telehealth room must have an acoustic environment that facilitates speech intelligibility and communication [2]. When planning for dedicated telehealth rooms like COMETECH e-health units, they should be located in a quiet area away from loud mechanical equipment, foot traffic, the central utility plant and exterior noise sources. A telehealth room also must be designed for the sound isolation rating appropriate for its clinical function $[2,10,12]$. In designing to achieve this minimum sound transmission class rating, consideration of all portions of the room envelope is recommended, including walls, floor/ceiling assemblies, doors and glazing, as well as field conditions that may affect the performance of those elements [2,22,23]. Additionally, background noise levels in telehealth bays, cubicles and rooms must be suitable for the clinical functions performed in the space. COMETECH e-health unit rooms maintain the minimum sound absorption coefficient for the room's clinical requirement and support sound isolation in any background noise or maintain it at the lowest levels.

Lighting. According to Dlaplus.com "direct frontal lighting is used in the space and it is recommended to use both direct and indirect lighting to reduce shadows and produce more accurate coloring in the transmitted image" [36]. Ontario Telehealth Network gives some very useful suggestions [29], as well as the First Nations of Quebec and Labrador Health and Social Services Commission [32]. For the COMETECH project, the room of the e-health unit provides the ability for direct frontal lighting. 
Equipment. In the COMETECH project, the e-health units are equipped with the specialized (tele-)medical devices that were provided in the previous section. Furthermore, web camera placement is critical $[36,37]$. The impact extends beyond a single room, requiring an assessment of network infrastructure, building services, power distribution and more. Even Web-based solutions using existing computers have potential impacts on a facility's design and physical infrastructure. Once again, the COMETECH project follows the guidelines prepared by the Ontario Telehealth Network regarding the necessary equipment of the e-health units regarding the electrical outlets, signage, tabletop and wall signs, clocks, and the required furniture [29].

\section{Discussion and Conclusions}

Patients with diabetes mellitus are usually asymptomatic, and the diagnosis of diabetes is delayed until serious complications develop. Therefore, the assessment of DM, obesity, and cardiovascular risk factors and the provision of up-to-date information on these diseases will increase the awareness of the population. This will reduce the occurrence of the above diseases in the targeted isolated areas.

Additionally, the costs related to DM, obesity and CVD are tremendous. Over a lifetime, DM imposes a substantial economic burden on healthcare systems. It has been calculated that the medical per person costs of treating DM and its complications, during a lifetime, is, on average, 85,200 Euros [18,19]. The total annual cost of DM, obesity and CVD in the EU is about 550 billion Euros $[18,19]$.

The key characteristic of COMETECH in the area of public health is that it achieves the involvement of patients and doctors, an integral and substantial part of the process of data collection for the examined diseases. In today's global environment, Europe is characterized by diversification with respect to cultural and historical aspects among its different nations and regions. However, despite the variety of these aspects, one could easily observe some shared elements and values throughout such regions. Cross-border co-operation is a significant tool for socioeconomic integration among different countries, especially in the fragmented region of Southeast Europe, which can be characterized by small internal markets, deficiencies in cross-border infrastructures, and to a certain extent, trans-border political tensions and conflicts. Nowadays, this is especially true due to the migration crisis that involves both countries.

The COMETECH project aims to introduce and support Primary Care, making this a serious contribution to the improvement of health services of both countries in a commonly shared region that has been economically neglected to a substantial degree by both of them. In the context of the cross-border co-operation between the targeted countries, the need to overcome certain obstacles that characterize their relationship is crucial, since it presents the lowest level of mutual trust within the EU, with only $55 \%$ of the responders feeling comfortable in working with a partner from their neighboring country, while the average percentage in $\mathrm{EU}$ is $82 \%$. In parallel, both countries present very low employment rates in the social economy sector compared with the EU average. These elements provide an opportunity for the promotion and encouragement of social ventures within the crossborder areas of two countries.

The four e-health units offer to the citizens of the targeted areas a professionally designed, point-of-care service that includes immediate, high-definition video consults, integrated peripheral and biometric devices for high quality, real-time exams, self-guiding, intuitive technology, and a nationwide, board-certified physician network, available 24/7/365. After each visit, the patients receive a comprehensive electronic summary of any notes, diagnoses, prescriptions, and follow-ups from the visit for diabetes mellitus, obesity and cardio vascular disease. This summary can be shared with treating physicians at any time to support continuity of care. It is expected that the solution's benefits and viable advantages will include significant resource savings, high convenience of the telemonitoring regime, coordination on all healthcare levels, and better support of clinical decisions, 
qualitative and effective healthcare provisions, as well as the possibility of using big data for decision makers.

This paper clarifies the minimum requirements for the use of telehealth systems as data sources for clinical research today, in order to ensure the reliability of clinical research data. Early clarification of the requirements for clinical telehealth research (both for clinical study conduct and research uses secondary to this) can facilitate their incorporation into any telehealth development work working today, and into plans for future expansion of these systems. Further to this document, user requirements of the software application will be mapped to HL7 and EuroRec functional models in separate deliverables and will be submitted to these organizations in their respective formats.

The findings of the paper are in accordance with those of Jaana and Pare [38] and others [10-13], suggesting that patients and providers will need to demonstrate continued ongoing compliance and favorable medical and economic results before these programs will be funded on a widespread basis for long-term care. Moreover, as Klonoff [39] points out, telemedicine systems are hindered by technical and structural problems that are being corrected gradually and will likely be solved in the near future.

Author Contributions: Supervision, conceptualization and methodology, K.K., resources writingoriginal draft preparation D.F., visualization, writing-review and editing M.T. All authors have read and agreed to the published version of the manuscript.

Funding: This research was funded by Interreg Pre-Accession Assistance (IPA) Cross Border Cooperation (CBC) Programme "Greece-Republic of North Macedonia 2014-2020" co-financed by the European Union under the Instrument for Pre-Accession Assistance (IPA II). Project co-funded by the European Union and national funds of the participating countries.

\section{Interreg - IPA CBC \\ Greece- Republic of North Macedonia
COMETECH}

Disclaimer: The views expressed in this publication do not necessarily reflect the views of the European Union, the participating countries and the Managing Authority.

Institutional Review Board Statement: Not applicable.

Informed Consent Statement: Not applicable.

Conflicts of Interest: The authors declare no conflict of interest.

\section{References}

1. Ekeland, G.; Bowes, A.; Flottorp, S. Effectiveness of telemedicine: A systematic review of reviews. Int. J. Med. Inform. 2010, 79, 736-771. [CrossRef]

2. ASHE FGI. Lays Out Telehealth Guidelines. 2018. Available online: https://www.hfmmagazine.com/articles/3337-fgi-lays-outtelehealth-guidelines?utm_medium=email\&utm_source=newsletter\&utm_campaign=pdcnews\&utm_content=20180509\&eid= $371822167 \& b i d=2095993$ (accessed on 30 January 2021).

3. Caffery, L.J. Telehealth interventions for reducing waiting lists and waiting times for specialist outpatient services: A scoping review. J. Telemed. Telecare 2016, 22, 504-512. [CrossRef]

4. Moffatt, J.; Diann, E. The reported benefits of telehealth for rural Australians. Aust. Health Rev. 2010, 34, 276-281. [CrossRef] [PubMed]

5. Smith, A.; Thomas, E.; Snoswell, C.; Haydon, H.; Mehrotra, A.; Clemensen, J.; Caffery, L. Telehealth for global emergencies: Implications for coronavirus disease 2019 (COVID-19). J. Telemed. Telecare 2020, 26, 309-313. [CrossRef] [PubMed]

6. Doarn, R.; Merrell, C. Telemedicine and e-health in disaster response. Telemed. e-Health 2014, 20, 605-607. [CrossRef] [PubMed]

7. Zhou, X.; Snoswell, C.; Harding, L.; Bambling, M.; Edirippulige, S.; Bai, X.; Smith, A. The Role of Telehealth in Reducing the Mental Health Burden from COVID-19. Telemed. e-Health 2020, 26, 377-379. [CrossRef] [PubMed]

8. Carter, L.; Nunlee-Bland, G.; Callender, C. A patient-centric, provider-assisted diabetes telehealth self-management intervention for urban minorities. Perspect. Health Inf. Manag. 2011, 8, 1b. [PubMed]

9. Kaufman, R.; Starren, J.; Patel, L.; Morin, C.; Hilliman, C.; Pevzner, J. A cognitive framework for understanding barriers to the productive use of a diabetes home telemedicine system. In American Medical Informatics Association Symposium; Musen, M.A., Friedman, C.P., Teich, J.M., Eds.; American Medical Informatics Association: Bethesda, MD, USA, 2003; pp. 356-360. 
10. Odom, J.; Stancil, M.; Nelson, B.; Russ-Sellers, R.; Schwecke, N.; Dawson, J.; Reulbach, L.; Burns, A.; Lindholm, M.; Bruch, J. Improving Diabetes Control through Remote Glucose Monitoring in a Diabetes Self-Management Program for Employees of a Health System. Clin. Diabetes 2019, 37, 203-210. [CrossRef]

11. Tang, P.; Overhage, J.; Chan, A.; Brown, N.; Aghighi, B.; Entwistle, M.; LuiHui, S.; Hyde, S.; Klieman, L.; Mitchell, C.; et al. Online disease management of diabetes: Engaging and Motivating Patients Online With Enhanced Resources-Diabetes (EMPOWER-D), a randomized controlled trial. J. Am. Med. Inform. Assoc. 2013, 20, 526-534. [CrossRef]

12. Hanlon, P.; Daines, L.; Campbell, C.; McKinstry, B.; Weller, D.; Pinnock, H. Telehealth Interventions to Support Self-Management of Long-Term Conditions: A Systematic Metareview of Diabetes, Heart Failure, Asthma, Chronic Obstructive Pulmonary Disease, and Cancer. J. Med. Internet Res. 2017, 19, 172-181. [CrossRef] [PubMed]

13. Crossen, S.; Raymond, J.; Neinstein, A. Top 10 Tips for Successfully Implementing a Diabetes Telehealth Program. Diabetes Technol. Ther. 2020, 22, 920-928. [CrossRef]

14. Krupinski, E. Telemedicine Workplace Environments: Designing for Success. Healthcare 2014, 2, 139-146. [CrossRef] [PubMed]

15. World Health Organization, Regional Office for Europe. Diabetes: Data and Statistics. 2021. Available online: https://www.euro who.int/en/health-topics/noncommunicable-diseases/diabetes/data-and-statistics (accessed on 30 January 2021).

16. James, W. World Health Organization recognition of the global obesity epidemic. Int. J. Obes. 2008, 32 (Suppl. 7), S120-S126. [CrossRef] [PubMed]

17. Eurostat Statistics Overweight and Obesity-BMI Statistics. 2014. Available online: https://ec.europa.eu/eurostat/statisticsexplained/index.php/Overweight_and_obesity_-_BMI_statistics (accessed on 30 January 2021).

18. World Health Organization, Regional Office for Europe Nutrition. Physical Activity and Obesity Greece. 2013. Available online: https://www.euro.who.int/_data/assets/pdf_file/0013/243301/Greece-WHO-Country-Profile.pdf (accessed on 30 January 2021).

19. European Commission, OECD. Health at a Glance: Europe State of Health in the EU Cycle. 2018. Available online: https: / / ec.europa.eu/health/sites/health/files/state/docs/2018_healthatglance_rep_en.pdf (accessed on 30 January 2021).

20. European Commission, OECD. Health at a Glance: Europe State of Health in the EU Cycle. 2020. Available online: https: / / ec.europa.eu/health/sites/health/files/state/docs/2020_healthatglance_rep_en.pdf (accessed on 30 January 2021).

21. World Health Organization. Investing in Health for Economic Development. 2004. Available online: https://www.who.int/ macrohealth/action/sintesis15novingles.pdf (accessed on 30 January 2021).

22. Hume, R.; Looney, J. Designing for Telehealth Spaces, Planning for the Next Generation of Health Care Delivery. 2016. Available online: https: / www.hfmmagazine.com/articles/1889-designing-for-telehealth-spaces (accessed on 30 January 2021).

23. Facility Guidelines Institute Guidelines for Design and Construction. 2018. Available online: https://fgiguidelines.org/ guidelines/2018-fgi-guidelines/ (accessed on 22 August 2020).

24. California Telehealth and eHEALTH Center (CTEC). Telehealth Room Design, Program Guide; CTRC: Augusta, GA, USA, 2011.

25. PHSA. Guidelines for Telehealth Rooms Used by the Provincial Health Services Authority in Canada. 2015. Available online: http:/ / www.phsa.ca/Documents/Telehealth/TH_Clinical_Guidelines_Sept2015.pdf (accessed on 12 August 2020).

26. Krupinski, E.; Burdick, A.; Pak, H.; Bocachica, J.; Earles, L.; Edison, K.; Goldyne, M.; Hirota, T.; Kvedar, J.; McKoy, K. American Telemedicine Association's Practice Guidelines for Teledermatology. Telemed. e Health 2008, 14, 289-302. [CrossRef] [PubMed]

27. Krupinski, E.A. Medical grade vs. off-the-shelf color displays: Influence on observer performance and visual search. J. Digit. Imaging 2009, 22, 363-368. [CrossRef] [PubMed]

28. Turvey, C.; Coleman, M.; Dennison, O.; Drude, K.; Goldenson, M.; Hirsch, P.; Jueneman, R.; Kramer, G.M.; Luxton, D.D.; Maheu, M.M. ATA Practice Guidelines for Video-Based Online Mental health Services. Telemed. e Health 2013, 19, 722-730. [CrossRef] [PubMed]

29. Ontario Telehealth Network (OTN). Telehealth Space Location and Preparation Guidelines. Telehealth Space Location and Preparation. 2013. Available online: https://support.otn.ca/sites/default/files/space_and_location_guideline.pdf (accessed on 30 January 2021).

30. Major, J. Telehealth room design. J. Telehealth Telecare 2005, 11, 10-14. Available online: https://telehealth.arizona.edu/sites/ telehealth.arizona.edu/files/Fundamental_TelehealthRoomDesign.pdf (accessed on 30 January 2021). [CrossRef] [PubMed]

31. Collins, J. Lighting design \& layout of a telemedicine conference room. Telemed. Today 1996, 4, $26-28$.

32. First Nations of Quebec and Labrador Health and Social Services Commission. Teleconsultation Room Design. 2016. Available online: http: / / www.cssspnql.com/docs/default-source/centre-de-documentation/doc_telesante_salle_eng_web.pdf?sfvrsn=2 (accessed on 30 January 2021).

33. Muther, R.; Hales, L. Systematic Layout Planning, 4th ed.; Management and Industrial Research Publication: Marietta, GA, USA, 2015.

34. Muther, R. Systematic Layout Planning; Cahners Books: Boston, MA, USA, 1973.

35. Jain, S.; Yadav, K. Systematic Layout Planning: A Review of Improvement in Approach to Pulse Processing Mills. Int. Res. J. Eng. Technol. 2017, 4, 503-507.

36. Dlaplus.com. Telemedicine Design: The Future of Healthcare Design. 2019. Available online: https://dlaplus.com/pages/ telemedicine-design-the-future-of-healthcare-design (accessed on 30 January 2021). 
37. University of Colorado Denver. Telehealth Health Guide, Room Setup and Equipment Issues. Available online: http://www. tmhguide.org/site/epage/94034_871.htm (accessed on 12 May 2016).

38. Jaana, M.; Paré, G. Home telemonItoring of Patients with Diabetes: A Systematic Assessment of Observed Effects. J. Eval. Clin. Pract. 2007, 13, 242-253. [CrossRef]

39. Klonoff, D. Using Telemedicine to Improve Outcomes in Diabetes—An Emerging Technology. J. Diabetes Sci. Technol. 2009, 3, 624-628. [CrossRef] [PubMed] 